Original Article

\title{
LONG-TERM FOOD RESTRICTION AND DIABECON ADMINISTRATION AMELIORATES ALLOXAN- INDUCED HYPERGLYCEMIA, THYROID DYSFUNCTION, AND OXIDATIVE STRESS IN RAT.
}

\author{
JYOTI AGRAWAL ${ }^{*}$, ANAND KAR ${ }^{2}$ \\ ${ }^{1}$ Government College Umarban 454449, Dhar (M. P.) India, ${ }^{2}$ School of Life Sciences, Devi Ahilya University Takshshila Campus, Indore \\ 452017, (M. P.) India \\ *Email: jyotiagrawal111@rediffmail.com
}

Received: 20 Mar 2021, Revised and Accepted: 17 May 2021

\begin{abstract}
Objective: The comparative effects of food restriction (FR), Diabecon treatment (DT) and their combined therapy (FR+DT) were studied in the regulation of alloxan-induced diabetes mellitus, alterations in thyroid hormones (TH) and oxidative stress.

Methods: Young diabetic rats were either kept on 50\% FR and/or DT ( $2 \mathrm{gm} / \mathrm{Kg}$ body weight) for two months and then alterations in serum glucose, insulin, TH concentrations, hepatic glycogen and pancreatic antioxidants along with oxidative stress markers were evaluated.

Results: Significantly increased serum glucose, tissue stress markers with decreased $\mathrm{TH}$, hepatic glycogen $(\mathrm{P}<0.0001$ for all) and pancreatic antioxidants $(\mathrm{P}<0.05-0.001)$ were observed in diabetic rats. Rats kept on different therapies exhibited significant $(\mathrm{P}<0.05)$ improvements than diabetic rats in all studied parameters. FR+DT group showed a significantly more decrease in serum glucose $(\mathrm{P}<0.05)$ that FR or DT group, while in other parameters improvement was found to be more or less equally improved in all treated groups.
\end{abstract}

Conclusion: FR appeared to mimic the effects of Diabecon in most of the indices. However, FR+DT appears to be more effective. Possibly both therapies ameliorate diabetes and oxidative stress following some common metabolic pathways.

Keywords: Food restriction, Insulin, Diabetes, Thyroid hormones, Oxidative stress, Diabecon

(C) 2021 The Authors. Published by Innovare Academic Sciences Pvt Ltd. This is an open access article under the CC BY license (https://creativecommons.org/licenses/by/4.0/) DOI: https://dx.doi.org/10.22159/ijpps.2021v13i7.41522. Journal homepage: https://innovareacademics.in/journals/index.php/ijpps.

\section{INTRODUCTION}

Diabetes mellitus (DM) and thyroid disease have become the most common endocrine abnormalities in recent years $[1,2]$. On one hand, insulin is found to affect thyroid functions in many ways, and on the other hand, thyroid hormones $(\mathrm{TH})$ regulate carbohydrate, protein, lipid metabolism and pancreatic function [3]. Thus, abnormality in one may negatively influence the effects of the other $[4,5]$. However, the exact mechanism of such interdependent complications is not well understood yet [6]. Of course, excessively generated free radicals were observed as an essential factor, which is believed to impair endocrine control and worsen metabolism [7].

Though, food restriction (FR) can improve these alterations by diminishing free radical generation and enhancing the expression of genes involved in antioxidant defense, insulin sensitivity, $\beta$-cell functions, nutrient metabolism; many times patients are unable to comply with this for a long time [6, 7]. Therefore, alternative drug treatment is very often required that can mimic the effects of FR. Since, some phytochemicals are known to have antidiabetic, antioxidative and TH regulatory potential $[8,9]$, which also share some biochemical signaling pathways with FR $[2,9]$, we thought of using a multi-herb preparation along with FR. Here, Diabecon (a poly-herbal formulation) was taken as test drug. It is a mixture of forty-two medicinal herbs, having protective activities $[10,11]$, but its effect on diabetic complications including $\mathrm{TH}$ concentration was not studied, till date. Thus, the aims of this study were to investigate whether, Diabecon administration can mimic the effects of prolonged FR in young non-obese diabetic rats and, to determine the additive combined effects of FR+Diabecon treatment if any. We evaluated the alterations in serum glucose, insulin, hepatic glycogen and $\mathrm{TH}$ concentrations. As, hyperglycemia deteriorates the pancreatic antioxidant system $[4,7,8]$, the possible free radical protective activities were also measured in the pancreas.

\section{MATERIALS AND METHODS}

Chemicals and drug

All chemicals were of reagent grade. Radioimmunoassay (RIA) kits for estimation of total serum insulin, $\mathrm{T}_{3}$ and $\mathrm{T}_{4}$ were purchased from
Beckman Coulter, New Delhi, India. Diabecon (Himalaya Drug Company, Bangalore, India, Batch no. 37200283B) was purchased from the registered local market store. Aqueous suspension of Diabecon was prepared in $0.5 \%$ Carboxymethylcellulose (CMC), a suspending agent and the drug was administered at a constant volume of $0.1 \mathrm{ml} / \mathrm{rat}$, p. o., for two months.

\section{Animals}

Healthy Wistar male rats of $118 \pm 12$ g (aged 4-5 w) from the departmental animal house were taken and used. They were provided standard rat feed, drinking water and kept in optimum environmental conditions.

\section{Experimental design}

Thirty-five rats were divided into five groups of seven each. Group 1 (Control) and Group 2 (diabetic) received only $0.1 \mathrm{ml}$ aqueous suspension of $0.5 \%$ CMC with normal diet. While group 3 (DT) animals were given a normal diet with Diabecon at $2 \mathrm{~g} /$ day, group 4 (FR) was devoid of food by $50 \%$, but given $0.1 \mathrm{ml}$ of $0.5 \%$ CMC without any drug; animals of group 5 (DT+FR) were kept at $50 \%$ $\mathrm{FR}$, but received Diabecon at $2 \mathrm{~g} /$ day for consecutive $60 \mathrm{~d}$. $0 \mathrm{n} 45^{\text {th }}$ day, $16 \mathrm{~h}$ fasted animals of group 2-5 were given a single injection of $100 \mathrm{mg} / \mathrm{kg}$ (i. p.) of alloxan monohydrate prepared in normal saline as was standardized earlier [4], while those of group 1 received only $0.1 \mathrm{ml}$ normal saline to ascertain the effect of the vehicle if any. Drug was administered at a fixed time (10:00-11:00 $\mathrm{AM})$ of the day to avoid circadian variation. At the end of the experiment overnight fasted animals were sacrificed by cervical dislocation. Blood and tissue were collected and processed as described earlier [4, 8].

\section{Biochemical analysis and statistical analysis}

Total circulating serum insulin, T3 and T4 were estimated by RIA in Medicare hospital, Indore, India. Serum glucose was measured using commercially available kits (ERBA, Transasia Biomedicals Ltd., Solan, India), while activities of pancreatic antioxidants (SOD, CAT, 
GPx and GSH), oxidative stress markers (LPO, LOOH and Protein carbonyl) and liver glycogen content were estimated following the protocols as routinely used in our laboratory $[4,8,11]$.

All values were expressed as mean \pm SEM. Differences in mean values were compared using Prism software, version 5.1 for windows, Inc., La Jolla, CA, USA by one-way analysis of variance (ANOVA) followed by t-test. $\mathrm{P}<0.05$ was considered as statistically significant.

\section{RESULTS}

Diabetic rats showed a significantly increased level of serum glucose $(\mathrm{P}<0.0001)$ with concomitant decreased values of hepatic glycogen serum insulin, T3 and T4 $(\mathrm{P}<0.0001$, for all $)$ than control rats. In the same group a considerably increased level of pancreatic LPO, LOOH and protein carbonyl $(\mathrm{P}<0.001$, for all) was observed with a parallel decrease in the activities of SOD $(\mathrm{P}<0.01)$, CAT $(\mathrm{P}<0.01)$, GPx $(\mathrm{P}<0.001)$ and GSH $(\mathrm{P}<0.05)$.

Although rats kept on DT, FR and DT+FR showed significant improvement in serum glucose $(\mathrm{P}<0.0001$, for all), animals kept on combined therapy showed more decrease $(\mathrm{P}<0.05)$ than DT or FR rats. Moreover, increased values of serum insulin $(\mathrm{P}<0.001, \mathrm{P}<0.01$ and $\mathrm{P}<0.001$ respectively); $\mathrm{T} 3 \quad(\mathrm{P}<0.0001, \quad \mathrm{P}=0.138$ and $\mathrm{P}<0.0001$ respectively); $\mathrm{T} 4(\mathrm{P}<0.0001$, for all) and hepatic glycogen $(\mathrm{P}<0.001$, $\mathrm{P}<0.001$ and $\mathrm{P}<0.0001$ respectively) were found in DT, FR and DT+FR animals. In addition to this, DT rats showed considerably increased values of $\mathrm{T} 3(\mathrm{P}<0.001$ than $\mathrm{FR})$ and $\mathrm{T} 4(\mathrm{P}<0.001$ than $\mathrm{FR}$ and $\mathrm{DT}+\mathrm{FR})$; while no significant difference was seen in insulin and hepatic glycogen. In fact, animals of DT+FR groups showed increased hepatic glycogen $(\mathrm{P}<0.05)$ as compared to that of DT animals.
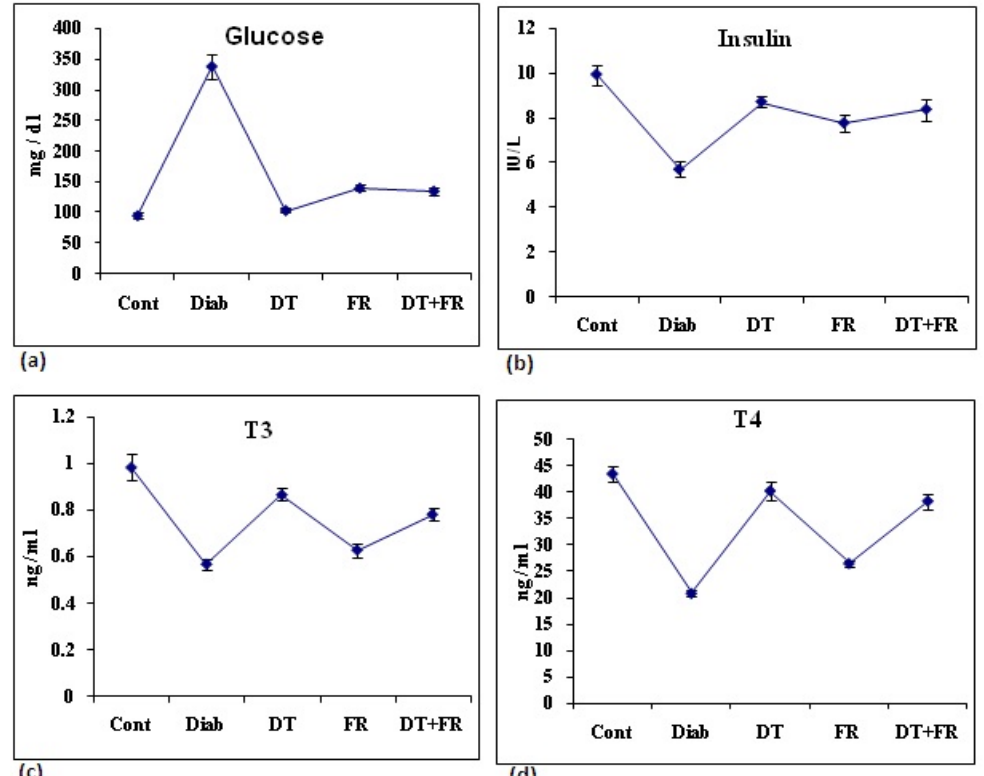

Fig. 1: Effects of different treatments on serum (a) Glucose, (b) Insulin, (c) T3 (triidothyronine) and (d) T4 (thyroxine). Cont, normal control group; Diab, diabetic group; DT, diabetic drug-treated group; FR, diabetic food-restricted group; DT+FR, diabetic drug+food restricted group. Each group has seven rats. Data expressed as mean \pm SEM
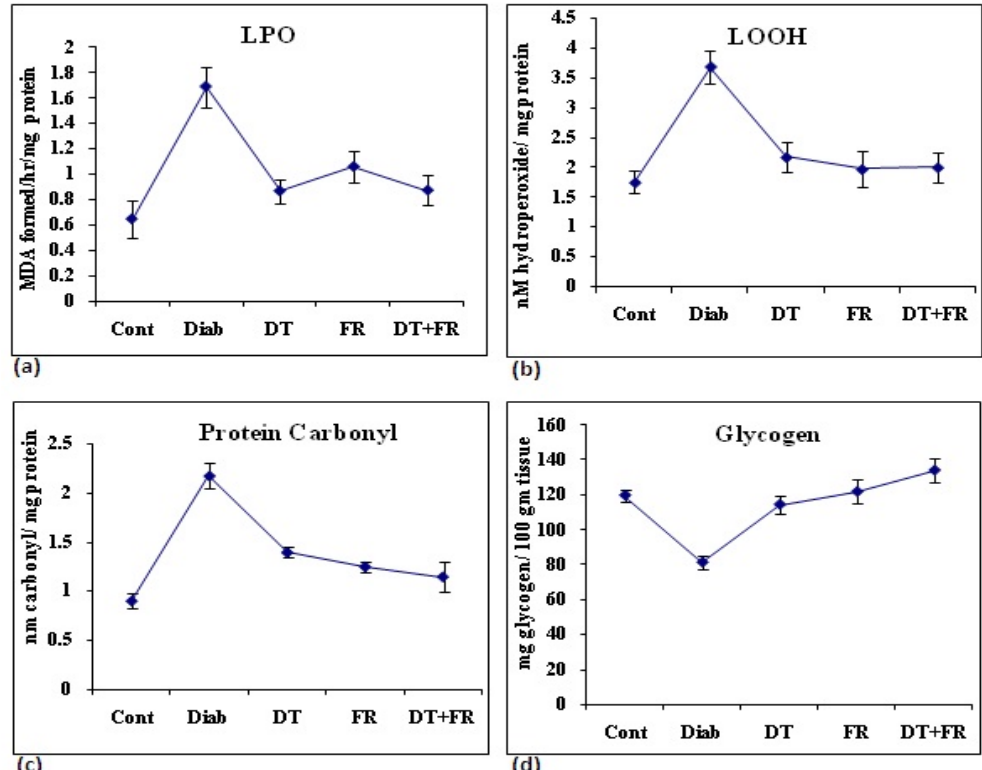

Fig. 2: Effects of different treatments on (a) LPO (lipid peroxidation), (b) LOOH (lipid hydroxide), (c) protein carbonyl of pancreatic tissue and (d) hepatic glycogen. Cont, normal control group; Diab, diabetic group; DT, diabetic drug-treated group; FR, diabetic food-restricted group; DT+FR, diabetic drug+food restricted group. Each group has seven rats. Data expressed as mean \pm SEM 


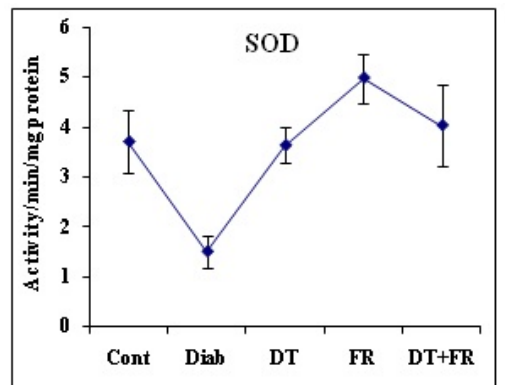

(a)

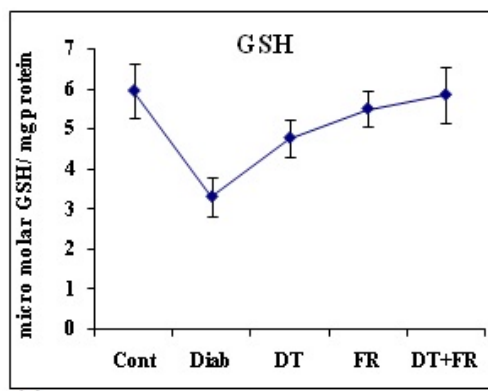

(c)

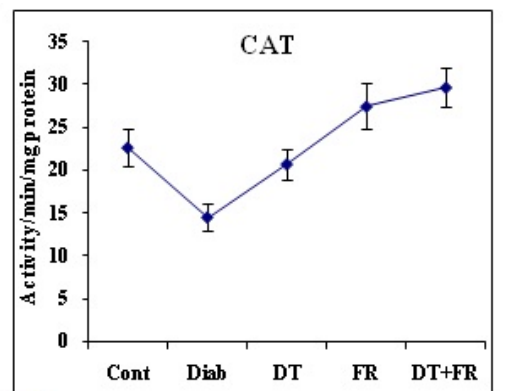

(b)

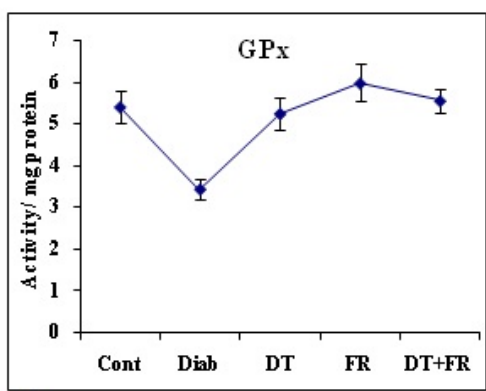

(d)

Fig. 3: Effects of different treatments on (a) SOD (superoxide dismutase); (b) CAT (catalase); (c) GPx (glutathione peroxidase) and (d) GSH (reduced glutathione) of pancreatic tissue. Cont, normal control group; Diab, diabetic group; DT, diabetic drug-treated group; FR, diabetic food-restricted group; DT+FR, diabetic drug+food restricted group. Each group has seven rats. Data expressed as mean \pm SEM

In case of pancreatic SOD, a significant increased activities were observed in DT $(\mathrm{P}<0.01)$, FR $(\mathrm{P}<0.001)$ and $\mathrm{DT}+\mathrm{FR}(\mathrm{P}<0.05)$ groups than the diabetic group. Similarly, in these groups, a marked increased activity was seen in CAT ( $\mathrm{P}<0.05, \mathrm{P}<0.01$ and $\mathrm{P}<0.01$ respectively), GPx $(\mathrm{P}<0.01, \mathrm{P}<0.001$ and $\mathrm{P}<0.001$ respectively) and $\mathrm{GSH}(\mathrm{P}<0.05$, $\mathrm{P}<0.01$ and $\mathrm{P}<0.001$ respectively). Furthermore, the values of LPO, $\mathrm{LOOH}$ and protein carbonyls were found to be decreased in DT $(\mathrm{P}<0.001, \mathrm{P}<0.01$ and $\mathrm{P}<0.001), \mathrm{FR}(\mathrm{P}<0.01, \mathrm{P}<0.01$ and $\mathrm{P}<0.001)$ and DT + FR $(\mathrm{P}<0.01, \mathrm{P}<0.001$ and $\mathrm{P}<0.001)$ group respectively. DT, FR and DT+DR animals exhibited no significant difference in studied oxidative stress markers, but, in case of CAT, animals given combined therapy showed significant increased value $(\mathrm{P}<0.01)$ than DT rats.

\section{DISCUSSION}

Present results revealed a better amelioration of alloxan-induced hyperglycemia by the FR+Diabecon as compared to their individual therapy. Although, in DT alone or in DT+FR treated groups a similar pattern of improvement was seen in liver glycogen, pancreatic antioxidants and tissue damage markers; a clear difference was observed in insulin and $\mathrm{TH}$ concentrations, suggesting that these two therapies possibly shared some metabolic signaling pathways but also served by their specific mechanism. The presently observed anti-hyperglycemic and protective effects of FR or Diabecon corroborate with the earlier reports $[2,10,11]$. However, this appears to be the first study revealing TH stimulatory efficacy of Diabecon either alone or with FR after chronic treatment.

Alloxan is a beta-cytotoxin and is commonly used as diabetogen [5]. Here also its deleterious effects on the pancreas and other body organs were evidenced by significantly increased blood glucose and diminished serum insulin, TH, glycogen and cellular antioxidants, similar to an earlier report [8] and it imitates the common features of diabetes $[2,4,8]$, which were found to be improved in DT, FR and FR+DT groups. The increased level of insulin in treated rats confirmed insulinotropic or $\beta$-cell protective activity of given therapies [12], although it was relatively less in FR rats. This is understandable because FR may reduce the circulatory insulin concentration, but it controls diabetes via increasing insulin sensitivity [6]. Additionally, in FR the total daily energy expenditure is also lessened by decreasing TH production [13].

SOD, CAT, GPx and GSH are chief defense antioxidants that counteract free radicals at different stages of their production [8, 14]. In hyperglycemia enhanced non-specific glycation of these defense machineries implies their decreased activities $[3,4]$ which lead to the formation of $\mathrm{LPO}, \mathrm{LOOH}$, protein carbonyls and other stress molecules [3]. FR has been reported to attenuate stress-sensitive signaling pathways such as NF-KB, JNK/SAPK, CREB and p38 MAPK [5] that also upregulate the activities of an antioxidative system [7]. In treated animals, improved tissue LPO, LOOH and protein carbonyl values and enhanced antioxidative activity might be considered as a sound argument in the induction of protective cell signaling pathways $[4,15]$.

In a parallel way, some polyphenolic and flavonoid compounds of tested drug such as allicine, diallyl trisulfide, trigonelline, momorcidin, charantin, gymnemic acid and azadirachtin activate genes involved in metabolism, antioxidant synthesis and $\beta$-cell proliferation $[8,12,15]$. On the other hand, these phytochemicals also control diabetes by suppressing the activity of $\alpha$-glucosidase and disaccharidases [12, 14]. As, both FR and herbal ingredients have been found to induce the AMPK mediated increased expression of SIRT1 and PGC- $1 \alpha$ genes that directly regulate krebs cycle, $\beta$ oxidation and protein synthesis $[5,9]$, which may also be responsible for the reduction of insulin resistance [3]. These findings further support the common as well as specific effects of the FR and drug treatment $[15,16]$.

Due to excessive free radical production diabetic patients are relatively more prone to cardiac problems, obesity, cancer, atherosclerosis, alzheimer disease and thyroid disorders [6], since, all these diseases are linked with oxidative stress [9], present treatment FR or DT or their combination may be adopted as an efficient remedy to prevent/delay these deformities.

\section{CONCLUSION}

In conclusion, similar to Diabecon, FR possesses beneficial health effects with respect to most of the studied indices in alloxan-induced diabetic rats. However, FR+Diabecon treatment appears to be a better option. It is presumed that FR and polyherbal drug act via some uncommon physiological pathways, which is revealed by additive effects in combined therapy. Then again, decreased tissue peroxidation and protein carbonylation with significantly increased antioxidative efficacy also revealed its protective effects against oxidative stress. Of course, well-controlled human studies are needed to ascertain the benefits of these therapies. 


\section{ACKNOWLEDGEMENT}

Financial support from University Grant Commission (UGC), New Delhi, India is gratefully acknowledged.

\section{AUTHORS CONTRIBUTIONS}

Dr. Jyoti Agrawal has done all the experimental work from animal feeding to biochemical analysis under the guidance and supervision of Dr. Anand Kar.

\section{CONFLICT OF INTERESTS}

\section{Declared none}

\section{REFERENCES}

1. Sharma H, Chandola HM. Prameha in ayurveda: correlation with obesity, metabolic syndrome, and diabetes mellitus. Part 2-management of Prameha. J Altern Complement Med 2011;17:589-99.

2. Pisarev MA. Inter-relationships between the pancreas and the thyroid. Curr Opin Endocrinol Diabetes Obes 2010;17:437-9.

3. Kahleova H, Matoulek M, Malinska H. Vegetarian diet improves insulin resistance and oxidative stress markers more than conventional diet in subjects with type 2 diabetes. Diabet Med 2011;5:549-59.

4. Archana D, Dixitha M, Santhy KS. Antioxidant and anti clastogenic potential of piper longum l. Inter J Appl Pharm 2015;7:11-4.

5. Rains JL, Jain SK. Oxidative stress, insulin signaling, and diabetes. Free Rad Biol Med 2011;50:567-75.

6. Ajala O, English P, Pinkney. Systematic review and metaanalysis of different dietary approaches to the management of type 2 diabetes. J Am J Clin Nutr 2013;97:505-16.

7. Jain R, Jain P, Jain P. A review on treatment and prevention of diabetes mellitus. Inter J Curr Pharm Res 2016;8:16-8.
8. Panda S, Kar A. Periplogenin-3-0--D-glucopyranosyl (1 $\rightarrow 6)-D-$ glucopyaranosyl-(1 $\rightarrow 4)$-D-Cymaropyranoside, isolated from Aegle marmelos protects doxorubicin-induced cardiovascular problems and hepatotoxicity in rats. Cardiovasc Ther 2009;27:108-16.

9. Ogbonna SU, Ezeani IU, Okafor CI, Chinenye S. Association between glycemic status and thyroid dysfunction in patients with type 2 diabetes mellitus. Diabetes Metab Syndr Obes 2019;12:1113-22.

10. Mitra R, Mazumder PM, Sasmal D. Comparative evaluation of the efficacy of some ayurvedic formulations in attenuating the progression of diabetic nephropathy. Pharmacologyonline 2010;1:709-17.

11. Agrawal J, Kar A, Panda S. Synergistic action of phytochemicals augments their antioxidative efficacy: an in vitro comparative study. Asian J Pharm Clin Res 2013;6:121-6.

12. Singh J, Cumming E, Manoharan G. Medicinal chemistry of the anti-diabetic effects of momordica charantia: active constituents and modes of actions. Open Med Chem 2011;5:70-7.

13. Luvizotto RA, Conde SJ, Sibio MT. Administration of physiologic levels of triiodothyronine increases leptin expression in calorie-restricted obese rats, but does not influence weight loss. Metabolism 2010;59:1-6.

14. Gutierrez RMP, Guzman MD. Meliacinolin: a potent $\alpha$ glucosidase and $\alpha$-amylase inhibitor isolated from azadirachta indica leaves and in vivo antidiabetic property in streptozotocin-nicotinamide-induced type 2 diabetes in mice. J Biol Pharma Bull 2012;35:1516-2415.

15. Kalra S, Aggarwal S, Khandelwal D. Thyroid dysfunction and type 2 diabetes mellitus: screening strategies and implications for management. Diabetes Ther 2019;10:2035-44.

16. Kavitha R. Antidiabetic and enzymatic antioxidant potential from ethanolic extracts of leaf and fruit of trichosanthes dioica and leaf of clitoria ternatea on diabetic rats induced by streptozotocin. Asian J Pharm Clin Res 2018;11:233-9. 